\title{
Development of a Simplified Theoretical Model for Dynamic Burst Time And Pressure of a Cylindrical Shell
}

\author{
Cunjiang Cheng* and G. E. Otto Widera \\ Bjorksten Research Lab, BIT 7, INC., Madison, Wisconsin \\ Center for Joining and Manufacturing Assembly, Marquette University, Milwaukee, Wisconsin
}

\begin{abstract}
The object of this study is to determine the short-term burst pressure and time of metal cylinders under shortterm dynamic loading conditions. A simplified theoretical model to calculate these dynamic burst time and pressure of cylindrical shells has been developed and the results are compared with finite element analysis (FEA) results via the use of the LS-DYNA code [1]. Based on the agreement between the two results, it can be concluded that a properly formulated simplified theoretical model can be employed with sufficient accuracy to determine the short-term dynamic burst pressures of metal cylinders.
\end{abstract}

Keywords: Cylindrical shell, Pipeline, Dynamic burst pressure, Dynamic burst time.

\section{INTRODUCTION}

The cylindrical shell is a basic structure that is used all over the world in the shipping, petrochemical, power, and aerospace industries as well as in others. Environmental pollution, property damage, personal injury, and even death can occur when a pressurized cylindrical shell bursts. Therefore, an accurate determination of the burst pressure of cylindrical shells is a critical parameter in the design process. Considerable work has been carried out to determine the static burst pressure using either analytical solutions, experimental studies, or finite element analysis. Dynamic loading such as water or steam hammer phenomena is also very common in a pipeline or piping.

In the 1950's, Cooper [2] developed an analytical equation to predict the static burst pressure for cylinders made of an isotropic ductile material. This equation provided the desired relationship between the burst pressure, material characteristics, original dimensions, and ultimate tensile strength of the material. At the same time, Svensson [3] derived a solution of the burst pressure for an arbitrary thick endcapped pipe based on the von-Mises yield criterion. Tadmor et al. [4] developed an analytical expression of the burst pressure of multilayered cylinders. They performed a large strain analysis, taking into consideration the elastic-plastic deformation with the Hill yield function and arbitrary hardening. An overall effective modulus was used to determine the onset of bursting, and they then derived the relations for thin-walled cylinders with the neglect of the elastic strains. Klever [5] presented an analytical model to determine the burst strength of the thin-wall uncorroded and corroded pipelines. The model results compared well with those of an uncorroded pipe test. Stewart et al. [6] re-examined the fundamental relationships that govern the equilibrium and stability

*Address correspondence to this author at the Bjorksten Research Lab, BIT 7, INC., Madison, Wisconsin; Tel: 608-224-0377; Fax: 608-224-0455; E-mail: cheng.cunjiang@gmail.com,geo.widera@mu.edu of a pipe under increasing internal pressure. Both Tresca's and von-Mises' yield criteria were considered. The authors concluded that their analytical model is suitable for both thin and thick-wall cases. Adachi et al. [7] proposed a mathematical solution for pipe elastic stress based on the assumption of one-dimensional propagation of the pressure and the quasi-static deformation of the pipe to calculate the elastic stresses in a tube due to water hammer. Leishear et al. [8-10] presented both an analytical solution and a finite element analysis to determine the dynamic pipe stress due to the vibrations created by water hammer with the assumptions that the material is linearly elastic and the water hammer load has been limited to a step pressure increase instead of a ramped pressure increase. He concluded that the maximum dynamic stress is twice that of the static stress when damping is ignored. Neither Adachi nor Leishear considered dynamic plastic deformation. Only a limited amount work has been published to determine the dynamic elastic stress in pipes, but no literature is available on the dynamic burst pressure of cylindrical shells.

\section{SIMPLIFIED THEORETICAL MODEL}

To make easily understand the effect of factors such as the pressure vs. time function, and the diameter vs. thickness ratio on the burst pressure as well as examine the consistency of the FEA results, a theoretical analysis method based on a simplified, thin-walled cylinder geometry is developed. Consider a thin-walled axisymmetric cylinder under uniform dynamic internal pressure. The geometry and behavior of this cylinder can be described by use of cylindrical coordinates $(r, \theta, z)$. Assume plane strain behavior. Assume further that the hoop stress $\sigma_{\theta}$ is the dominant stress and that it can be taken to be constant throughout the thickness of the cylinder.

With reference to Fig. (1), the summation of forces in the radial direction for an element of volume $h \cdot r \cdot d \theta \cdot d l$ is, 

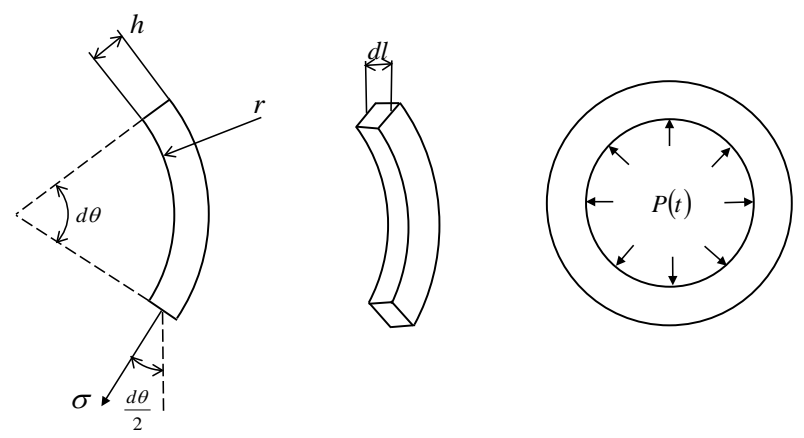

Fig. (1). Simplified Geometry and Loading Condition of Cylinder.

$\Sigma F_{r}=P(t) \cdot d \theta \cdot r \cdot d l-2 \cdot \sigma_{\theta} \cdot h \cdot d l \cdot \sin \left(\frac{d \theta}{2}\right)$

Assume that the mass of this small volume of the cylinder will remain constant; it can, therefore, be expressed as,

$$
m=\rho \cdot r_{0} \cdot d \theta \cdot h_{0} \cdot d l
$$

In the above, $h$ is the instantaneous wall thickness, $h_{0}$ the initial wall thickness, $d l$ the increment of cylinder length, $\rho$ the density, $r$ the instantaneous inside radius, $r_{0}$ the initial inside radius, and $d \theta$ the small increment in arc angle. Define the radial acceleration in $a_{r}$ as

$a_{r}=\frac{d^{2} r}{d t^{2}}=\ddot{r}$

When $d \theta$ is very small, the equation (4) can be established,

$\sin \left(\frac{d \theta}{2}\right) \approx \frac{d \theta}{2}$

Because the cylinder is assumed to be thin-walled, the acceleration can be taken to be constant throughout the thickness. The equation of motion in the radical direction for the volume element can thus be written as

$P(t) \cdot d \theta \cdot r \cdot d l-2 \cdot \sigma_{\theta} \cdot h \cdot d l \cdot \frac{d \theta}{2}=\rho \cdot r_{0} \cdot d \theta \cdot h_{0} \cdot d l \cdot \ddot{r}$

The assumption of volume constancy during the deformation process satisfies the following equation:

$$
\pi\left[\left(r_{0}+h_{0}\right)^{2}-r_{0}^{2}\right] d l=\pi\left[(r+h)^{2}-r^{2}\right] d l
$$

which yields

$$
h=\sqrt{r^{2}+2 r_{0} h_{0}+h_{0}^{2}}-r
$$

Equation (5) can now be written as

$$
\begin{aligned}
& P(t) \cdot \frac{r}{\sqrt{r^{2}+2 r_{0} h_{0}+h_{0}^{2}}-r}-\sigma_{\theta} \\
& =\rho \cdot \frac{h_{0}}{\sqrt{r^{2}+2 r_{0} h_{0}+h_{0}^{2}}-r} r_{0} \cdot \ddot{r}
\end{aligned}
$$

or

$$
\sigma_{\theta}=P(t) \cdot \frac{r}{\sqrt{r^{2}+2 r_{0} h_{0}+h_{0}^{2}}-r}-\rho \cdot \frac{h_{0}}{\sqrt{r^{2}+2 r_{0} h_{0}+h_{0}^{2}}-r} r_{0} \cdot \ddot{r}(9)
$$

For a very small increment of the radial strain, one can write

$d \varepsilon_{r}=\frac{d r}{r}$

One can integrate both side of the equation and obtain

$$
\varepsilon_{r}=\int_{r_{0}}^{r} \frac{1}{r} \cdot d r=\ln (r)-\ln \left(r_{0}\right)
$$

which yields

$$
r=r_{0} \cdot e^{\varepsilon_{r}}
$$

With a consideration of the existence of strain rate effects, the following equation can be developed to fit the material data relating stress, strain and strain rate curves by using MathCAD [11] software:

$\sigma=k \cdot \varepsilon^{n} \cdot\left[1+\left(\frac{\dot{\varepsilon}}{D}\right)^{\frac{1}{q}}\right]+z \cdot \varepsilon$

Here, $\sigma$ is the effective von-Mises stress, and $\varepsilon$ the effective von-Mises strain. Further, $z, k, q$ and $n$ are constants for a particular material.

The assumption of volume constancy during the deformation, also leads to the following equation:

$$
\varepsilon_{r}+\varepsilon_{\theta}+\varepsilon_{z}=0
$$

For plane strain, $\varepsilon_{z}=0$ and thus,

$$
\varepsilon_{\theta}=-\varepsilon_{r}
$$

The effective von-Mises strain is defined by the following equation:

$$
\varepsilon=\frac{\sqrt{2}}{3} \sqrt{\left(\varepsilon_{r}-\varepsilon_{\theta}\right)^{2}+\left(\varepsilon_{\theta}-\varepsilon_{z}\right)^{2}+\left(\varepsilon_{z}-\varepsilon_{r}\right)^{2}}
$$

For plane strain, it becomes

$$
\varepsilon=\frac{2 \sqrt{2}}{3} \varepsilon_{r}
$$


For a thin-walled cylinder, radius $r$ is much larger than the thickness $h$ and the radial stress $\sigma_{r}$ is small compared to the other two stresses. Therefore, one can assume,

$$
\sigma_{r}=0
$$

Also,

$$
\sigma_{z}=\frac{P(t) \cdot r^{2}}{(r+h)^{2}-r^{2}}
$$

The effective von-Mises stress $\sigma$ is defined by the following equation:

$$
\sigma=\frac{1}{\sqrt{2}} \sqrt{\left(\sigma_{\theta}-\sigma_{r}\right)^{2}+\left(\sigma_{\theta}-\sigma_{z}\right)^{2}+\left(\sigma_{z}-\sigma_{r}\right)^{2}}
$$

With the assumptions made, this expression can be solved for $\sigma_{\theta}$, and becomes

$$
\sigma_{\theta}=\frac{\sigma_{z}+\sqrt{4 \cdot\left(k \cdot \varepsilon^{n} \cdot\left[1+\left(\frac{\dot{\varepsilon}}{D}\right)^{\frac{1}{q}}\right]+z \cdot \varepsilon\right)^{2}+3 \sigma_{z}^{2}}}{2}
$$

Equating the equation (21) to the equation (9), one obtains

Substituting equations (7), (17) and (19) into the equation (22) results in:

$$
\sigma_{z}+\sqrt{4 \cdot\left(k \cdot \varepsilon^{n} \cdot\left[1+\left(\frac{\dot{\varepsilon}}{D}\right)^{\frac{1}{q}}\right]+z \cdot \varepsilon\right)^{2}+3 \sigma_{z}^{2}}
$$

2

$=P(t) \cdot \frac{r}{\sqrt{r^{2}+2 r_{0} h_{0}+h_{0}^{2}}-r}-\rho \cdot \frac{h_{0}}{\sqrt{r^{2}+2 r_{0} h_{0}+h_{0}^{2}}-r} r_{0} \cdot \ddot{r}$

$\frac{P(t) \cdot r^{2}}{2 \cdot r_{0} \cdot h_{0}+h_{0}{ }^{2}}+\sqrt{4 \cdot\left(k \cdot\left(\frac{2 \sqrt{2}}{3} \varepsilon_{r}\right)^{n} \cdot\left[1+\left(\frac{\frac{2 \sqrt{2}}{3} \dot{\varepsilon}_{r}}{D}\right)^{\frac{1}{q}}\right]+z \cdot \frac{2 \sqrt{2}}{3} \varepsilon_{r}\right)^{2}+3\left(\frac{P(t) \cdot r^{2}}{2 \cdot r_{0} \cdot h_{0}+h_{0}{ }^{2}}\right)^{2}}$

$=P(t) \cdot \frac{r}{\sqrt{r^{2}+2 r_{0} h_{0}+{h_{0}}^{2}}-r}-\rho \cdot \frac{2}{\sqrt{r^{2}+2 r_{0} h_{0}+{h_{0}}^{2}}-r} r_{0} \cdot \ddot{r}$
Here,

$$
\varepsilon_{r}=\ln (r)-\ln \left(r_{0}\right)
$$

The most general approach for the solution of the dynamic response of structural systems is the direct numerical integration of the dynamic equilibrium equations. Equation (23) is a very complicated differential equation based on the variable $r$. It cannot be solved directly by using the regular central difference method or the Newmark method [12]. Here, a similar explicit numerical method is developed based on the general central difference method. Thus,

$$
\begin{aligned}
& \ddot{r}_{t}=\frac{1}{\Delta t^{2}}\left(r_{t-\Delta t}-2 r_{t}+r_{t+\Delta t}\right) \\
& \dot{r}_{t}=\frac{1}{2 \Delta t}\left(-r_{t-\Delta t}+r_{t+\Delta t}\right)
\end{aligned}
$$

Combine the expressions of (24) with the equation (23), to obtain the equation (25):

heoretically, one can solve the equation (25) using the initial conditions of $r_{0}$ and $r_{1}$. Here, $r_{0}$ is the known initial inside radius. Radius $r_{1}$ can be solved from following equations: 


$$
\begin{aligned}
& \frac{p(t) \cdot r_{t}^{2}}{2 \cdot r_{0} \cdot h_{0}+h_{0}{ }^{2}}+\sqrt{\left(4 \cdot k \cdot\left(\frac{2 \sqrt{2}}{3} \ln \left(\frac{r_{t}}{r_{0}}\right)\right)^{n} \cdot\left[1+\left(\frac{\frac{2 \sqrt{2}}{3} \cdot \frac{\frac{1}{2 \Delta t}\left(-r_{t-\Delta t}+r_{t+\Delta t}\right)}{r_{t}}}{D}\right]+z \cdot \frac{2 \sqrt{2}}{3} \ln \left(\frac{r_{t}}{r_{0}}\right)\right]^{\frac{1}{q}}+3\left(\frac{p(t) \cdot r_{t}^{2}}{2 \cdot r_{0} \cdot h_{0}+h_{0}{ }^{2}}\right)^{2}\right.} \\
& 2 \\
& =P(t) \cdot \frac{r_{t}}{\sqrt{r_{t}^{2}+2 r_{0} h_{0}+h_{0}^{2}}-r_{t}}-\rho \cdot \frac{h_{0}}{\sqrt{r_{t}^{2}+2 r_{0} h_{0}+h_{0}^{2}}-r_{t}} r_{0} \cdot \frac{1}{\Delta t^{2}}\left(r_{t-\Delta t}-2 r_{t}+r_{t+\Delta t}\right)
\end{aligned}
$$$$
\dot{r}_{1}=\frac{2}{\Delta t}\left(-r_{0}+r_{1}\right)
$$$$
\ddot{r}_{1}=\frac{2}{\Delta t^{2}}\left(-r_{0}+r_{1}\right)
$$

Table 1. ASTM A-106B Material Description

\begin{tabular}{|c|c|c|c|c|c|}
\hline \multicolumn{5}{|c|}{ Chemical Analysis, \% } & న Condition \\
\hline \hline $\mathrm{C}$ & $\mathrm{Mn}$ & $\mathrm{P}$ & $\mathrm{S}$ & $\mathrm{Si}$ & \\
\hline 0.17 & 0.77 & 0.010 & 0.025 & 0.25 & Seamless hot-rolled \\
\hline
\end{tabular}

In the sample calculation, the cylindrical shell has an outCombining equations (26) and (27) with the equation (25), one obtains equation (28): side diameter of 14 inches and a wall thickness of 0.165

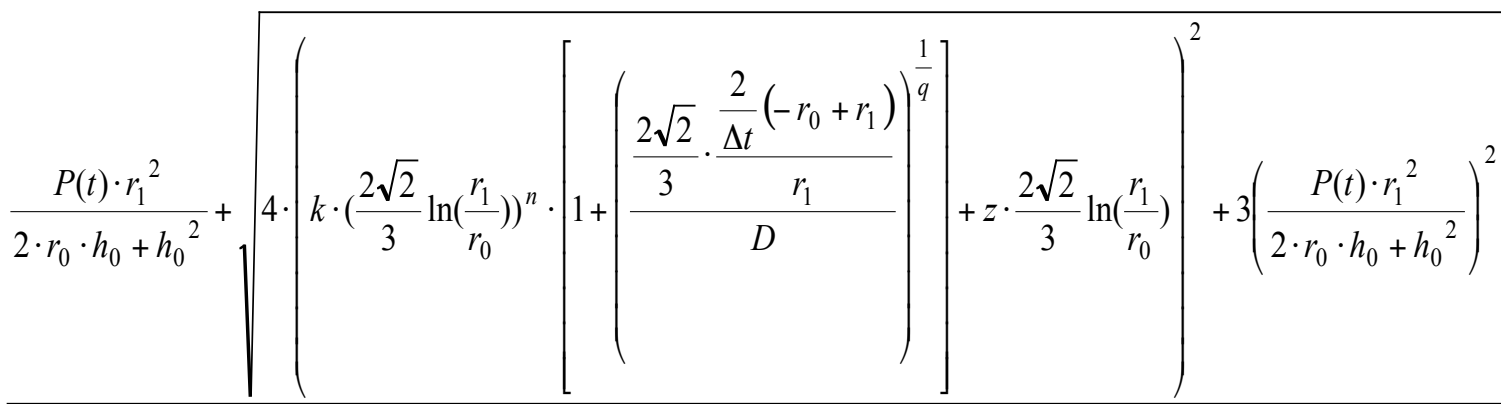

$$
\begin{aligned}
& 2 \\
& =P(t) \cdot \frac{r_{1}}{\sqrt{r_{1}^{2}+2 r_{0} h_{0}+h_{0}^{2}}-r_{1}}-\rho \cdot \frac{h_{0}}{\sqrt{r_{1}^{2}+2 r_{0} h_{0}+h_{0}^{2}}-r_{1}} r_{0} \cdot \frac{2}{\Delta t^{2}}\left(-r_{0}+r_{1}\right)
\end{aligned}
$$

In equation (28), the only unknown variable is $r_{1}$. Therefore, theoretically, it is solvable. However, due to the high non-linearity, it is difficult to solve this equation manually. Equation (28), and then equation (25), can be solved using a commercial mathematics software such as MathCAD [12]. To make sure that the equation (25) is always solvable, the incremental time step should be very small. However, when the time step is smaller than the minimum precision of the MathCAD software, the solution will be unstable.

A sample calculation is performed by using MathCAD. The material is ASTM106 steel [13]. The material description is listed in Table 1. The stress, stain and strain rate curves are shown in Fig. (2). By fitting the stress, strain, and strain rate curves one can get the material coefficients of $k, n$, $z$ and $q$. The pressure vs. time curve is taken as the ramped curve shown in Fig. (3). Here, the time td is pressure pulse duration.

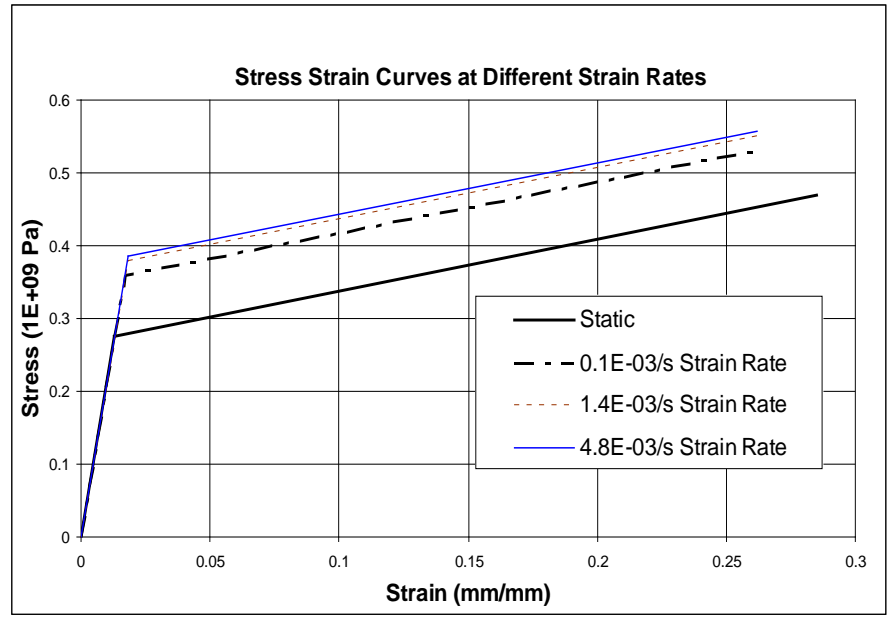

Fig. (2). Stress-strain Curve of A-106B Steel at Different Strain Rates. 


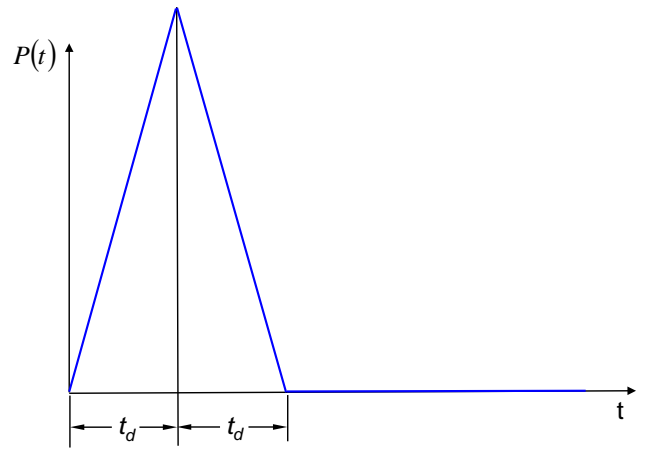

Fig. (3). Pressure (psi) vs. Time (second) Curve.

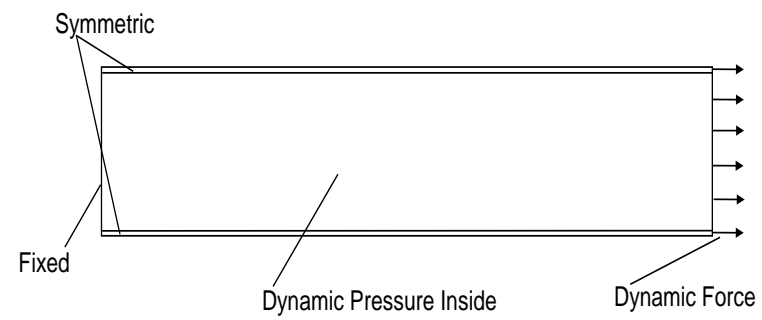

Fig. (4). FEA Model Loading and Boundary Conditions.

inches. The resulting burst time is about 5.04897 milliseconds when the peak pressure is 2200 psi.

To confirm these calculations a finite element analysis (FEA) is carried out using the dynamic computer code, LSDYNA [1]. In developing the FEA mesh, the eight node solid element is employed and the guidelines stated in reference [14] are followed. In particular, the mesh has three elements across the thickness (see Fig. 5) and the element size is 0.197 in. The boundary conditions and loading (see Fig. 4) are as follows:

1) One end is fixed, the other end is free.

2) Internal pressure is a function of time (see Fig. 3) with the maximum amplitude taken as 2500, 2200, 2000, 1800,

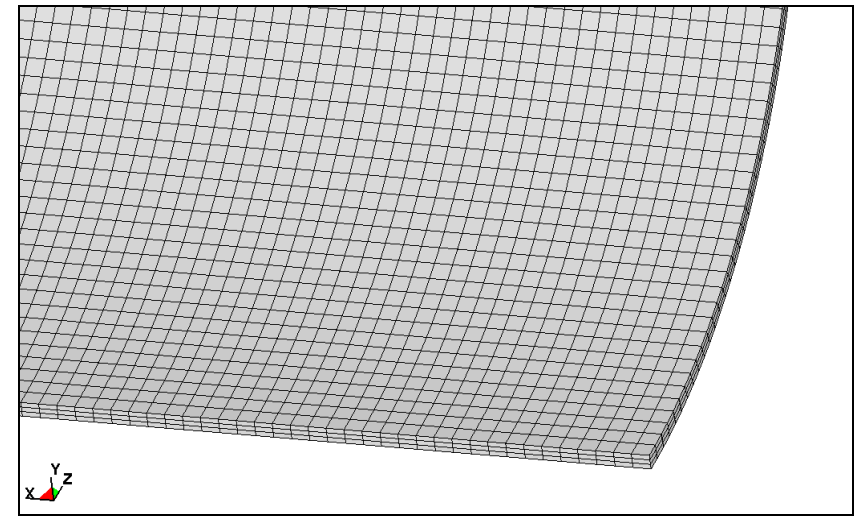

Fig. (5). FEA Mesh.

1760 and 1720 psi. A dynamic force equal to the pressure multiplied by the inside area of the cylinder is added at the free end.

3) Gravity acts along the $Y$ axis.

In the FEA simulation, the burst criterion is based on the maximum plastic strain at different strain rates. Once the plastic strain of an element reaches the maximum plastic strain for a certain stain rate, the element is deleted from the calculation. The burst pressure and time can be recorded from the output of the FEA model. More detailed setup, mesh, results and configurations can be found in reference [15].

Table 2 clearly shows that the burst pressure predicted by FEA is 1800 psi while that predicted by theoretical method is 1760 psi for the cylinder under consideration. The burst times are close as well.

\section{SUMMARY}

A simplified explicit numerical method to calculate the dynamic burst pressure and time of a thin-walled cylindrical shell is developed. A sample result from the use of this method is compared with FEA results and it is shown that the present simplified theoretical method can be used to accurately determine the burst pressure and time of a thinwalled cylindrical shell.

Table 2. Comparison of Equation (23) and FEA Results

\begin{tabular}{|c|c|c|c|c|c|}
\hline OD (inch) & Thickness (inch) & $\begin{array}{c}t_{d} \\
(\mathbf{m s})\end{array}$ & $\begin{array}{c}\text { Peak Pressure } \\
(\mathbf{p s i})\end{array}$ & FEA Burst Time (ms) & $\begin{array}{c}\text { Equation (23) } \\
\text { Burst Time (ms) }\end{array}$ \\
\hline \hline 14 & 0.165 & 3.9 & 2500 & 3.678 & 4.435 \\
\hline 14 & 0.165 & 3.9 & 2200 & 3.939 & 5.049 \\
\hline 14 & 0.165 & 3.9 & 2000 & 4.269 & 5.794 \\
\hline 14 & 0.165 & 3.9 & 1800 & 5.011 & 6.795 \\
\hline 14 & 0.165 & 3.9 & 1760 & No burst & 7.392 \\
\hline 14 & 0.165 & 3.9 & 1720 & No burst & No burst \\
\hline
\end{tabular}




\section{REFERENCES}

[1] LS-DYNA Theoretical manual, Livermore Software Technology Corporation, 1998.

[2] W.E. Cooper, "The significance of the tensile test to pressure vessel design," Welding Research Supplement, pp. 49-56, Jan, 1957.

[3] N.L. Svensson, "Burst pressure of cylindrical and spherical vessels," Journal of Applied Mechanics, vol. 25, No. 1, pp. 89-96, 1958.

[4] E.B. Tadmor and D. Durban, "Plastic deformation and burst of pressurized multilayered cylinders," Journal of Pressure Vessel Technology, vol. 117, pp. 85-91, Feb, 1995.

[5] F.J. Klever, "Burst strength of corroded pipe: flow stress revisited," Twenty-fourth annual Offshore Technology Conference, May 4-7, Houston, Texas, 1992.

[6] G. Stewart and F.J. Klever, "An analytical model to predict the burst capability of pipelines," $13^{\text {th }}$ International Conference on Offshore Mechanics and Arctic Engineering, vol. 5, Houston, Texas, Pipeline Technology, 1994.

[7] T. Adachi, S. Ujihashi and H. Matsumoto, "Impulsive responses of a circular cylinder shell subject to water hammer waves," Journal of Pressure Vessel Technology, vol. 113, pp. 517-523, Nov, 1991.

[8] R.A. Leishear, C.A. Young and E. M. Alford, "Dynamic pipe stresses during water hammer, I, finite element approach," Design and Analysis of Piping, Vessels and Components, 2002 ASME
Pressure Vessels and Piping Conference, Vancouver: British Columbia, Canada, August 5-9, 2002.

[9] R.A. Leishear, "Dynamic pipe stresses during water hammer, II, a vibration analysis," Design and analysis of piping, vessels and components, 2002 ASME Pressure Vessels and Piping Conference, Vancouver: British Columbia, Canada, August 5-9, 2002.

[10] R.A. Leishear, "Dynamic pipe stresses during water hammer, III, complex stresses," Design and analysis of piping, vessels and components, 2002 ASME Pressure Vessels and Piping Conference, Vancouver: British Columbia, Canada, August 5-9, 2002.

[11] MathCAD 13 User's Guide, Mathsoft Engineering \& Education, Inc., Cambridge, MA, USA, 2005.

[12] N.M. Newmark, "A method of computation for structural dynamics," Journal of Engineering Mechanics Division, ASCE, (EM3) vol. 85 , pp. 67-94, 1959

[13] D. Peterson, "Pipe whip dynamics: an experimental and analytical investigation," Ph.D. Dissertation, University of Akron, 1982.

[14] G.E.O. Widera and L.P. Xue, "Guidelines for FEA fodeling of cylinder-to-cylinder Intersections," WRC Bulletin No. 493, New York: Welding Research Council, 2004.

[15] C. Cheng and G.E.O. Widera, "Dynamic burst pressure simulation of cylindrical shells," in Proceedings of the 2008 ASME Pressure Vessels \& Piping Conference, Chicago, IL, USA, July 27-31, 2008.

Received: June 03, 2008

Revised: January 21, 2009

Accepted: January 22, 2009

(C) Cheng and Widera; Licensee Bentham Open.

This is an open access article licensed under the terms of the Creative Commons Attribution Non-Commercial License (http://creativecommons.org/licenses/by-nc/3.0/) which permits unrestricted, non-commercial use, distribution and reproduction in any medium, provided the work is properly cited. 